\title{
Tests of ventilatory function for use in long-term animal studies
}

\author{
D. M. HIETT \\ Department of Occupational Health, University of Manchester
}

\begin{abstract}
Hiett, D. M. (1974). British Journal of Industrial Medicine, 31, 53-58. Tests of ventilatory function for use in long-term animal studies. Techniques for use in long-term experiments to measure total resistance and total compliance of the guinea-pig ventilatory system are described. The resonance characteristics, required for use of the forced oscillation techniques to determine total resistance, were satisfied by the guinea-pig ventilatory system, and the resonant frequency of these animals was found to be $32 \mathrm{~Hz}$.

The total resistance and total compliance techniques were tested to determine the variability of repeated measurements on individual animals, on groups of animals, and on groups of animals measured over intervals of time. A coefficient of variation of less than $20 \%$ was found for repeated measurements on individuals and groups of animals. A gradual increase in total compliance and decrease in total resistance occurred over a period of several weeks when the animals were maturing. Values of $0.13 \mathrm{ml} / \mathrm{cmH}_{2} \mathrm{O}$ for total compliance and $0.40 \mathrm{~cm} \mathrm{H}_{2} \mathrm{O} / \mathrm{ml}$ per second for total resistance were found for young guinea-pigs $(250-500 \mathrm{~g}$ weight), and these are similar to previously reported pulmonary values for similar guinea-pigs.

The value of total measurements of ventilatory function of the complete animal when detecting changes in the lung alone are discussed with respect to guinea-pigs.

The tests are believed to be adequately sensitive and practicable for long-term studies of ventilatory function.
\end{abstract}

Many materials of industrial importance are known to cause lung disease with impairment of ventilatory function. Little work has been carried out on changes in ventilatory function during the development of such diseases in experimental animals. This may be due partly to lack of documentation of suitable techniques.

Mead (1960) has mentioned techniques to measure total resistance and total compliance that do not require surgical procedures and so can be used repeatedly on individual animals. Instead, pressures are applied around the thorax by means of a partial body plethysmograph, and the resulting flows of air and volume changes are measured at the airways opening.

When measuring total resistance, the pressure change must be both sinusoidal and of constant frequency, as the method depends on the thorax being brought into resonance. Mead (1960) produced oscillation by hand pumping a syringe, which could only approximate the required conditions. Swann, Brunol, and Balchum (1965) improved the technique by using an electric diaphragm pump to produce a constant frequency sinusoidal oscillation, but none of these workers has demonstrated that the necessary resonance characteristics are met by the mechanical responses of the guinea-pig ventilatory system.

The method of total compliance measurement used by Mead (1960) is more straightforward and requires measurement of volume change during a change in transthoracic pressure (airways opening to body surface). The measurement of total resistance by this method, therefore, requires validation by study of the mechanical responses of the ventilatory 
system. For both the resistance and compliance methods the repeatability of results obtained requires investigation.

\section{Methods}

\section{Experimental animals}

Specific pathogen-free (SPF) guinea-pigs were used in this investigation. Guinea-pigs were chosen as they are amenable to handling when not anaesthetized and the SPF variety was used because during long-term experiments such animals are free from spontaneous respiratory disorders (King, 1966).

\section{Resistance determination}

The technique is based on the theoretical assumption that the ventilatory system can be brought into resonance by applying a sinusoidal pressure oscillation, at a certain frequency, externally around the thorax. The impedance is measured as the ratio of the amplitude of this applied pressure oscillation to the amplitude of the resultant flow oscillation measured at the airways opening. At the point of resonance the impedance is dependent only on the flow resistance of the system.

The required extrathoracic pressures were applied to the animal in a partial body plethysmograph (Fig. 1) essentially similar to that described by Swann and coworkers (1965). Pressure measurements were made from outlet A by connection to a Statham strain gauge (P23 series) with amplification by a carrier preamplifier (Honeywell 2585).

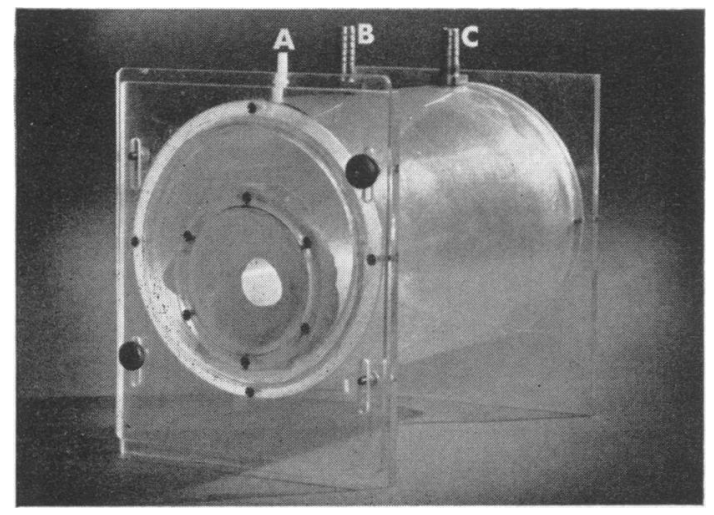

FIG. 1. Guinea-pig plethysmograph showing connectors for pressure measurements (A), pressure application (B), and pressure adjustment (C).

Sinusoidal oscillating pressure was generated by a variable speed electric motor driving a piston that acted against a highly elastic rubber diaphragm stretched over one end of a rigid Perspex cylinder. The other end of the cylinder was connected by rubber tubing to the plethysmograph inlet B above the animal's thorax. A length of tubing was connected to the rear outlet hole $C$ of the plethysmograph and served the dual purpose of letting slow pressure changes due to respiratory movements leak away and improved applied sinusoidal pressure changes at higher frequencies. The plethysmographic pressure oscillations so produced were indistinguishable from the output of an electronic sine wave generator.

Flow of air at the airways opening (the nostrils) was monitored by a pneumotachograph (Fleisch 0000) attached to a face mask which was made of transparent, slightly pliable plastic fitting snugly over the animal's snout. The mask was held firmly in position so that the nostrils were in close proximity to the pneumotachograph opening, thus minimizing dead space. The pressure differences across the pneumotachograph were detected by a differential pressure transducer (Hewlett and Packard 270) and amplified by a carrier preamplifier (Sanborn 350-1100C).

The impedance of the ventilatory system was measured at several frequencies of pressure oscillation. The measurements were made from pressure/flow Lissajous loops, as described by Swann and co-workers (1965). The X axis of the oscilloscope (Telequipment D43R) was calibrated to $2 \mathrm{cmH}_{2} \mathrm{O} / \mathrm{cm}$ deflection by using a water manometer, and the $Y$ axis to $4 \mathrm{ml} / \mathrm{sec} / \mathrm{cm}$ deflection. The flow calibration was originally carried out by applying known flows to the pneumotachograph, but once the characteristics of the pneumotachograph were determined electronic calibration was possible. The calibration was checked periodically by the original method but remained constant. Pressure/flow loops were photographed (Shackman AC2/23 camera) at each frequency; the impedance was proportional to the cotangent of the gradient of such loops (Fig. 2). All impedance measurements were made from loops occurring during the expiratory phase of respiration.

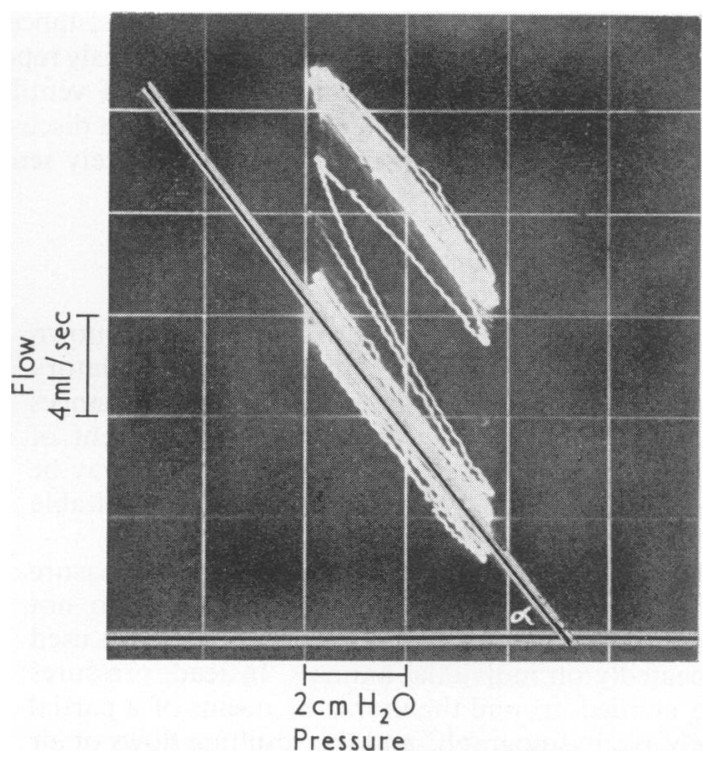

FIG. 2. Photograph of pressure/flow loops. Flow signals were applied to the vertical axis and pressure signals to the horizontal axis. The expiratory angle $a$ is proportional to the expiratory resistance. 
Compliance determination

Total compliance was determined by measuring the volume change at the airways opening resulting from change in transthoracic pressure. The volume measurements were made at end expiratory points to remove flow resistive components, and because during normal breathing expiration is essentially passive, the ventilatory musculature is relaxed at such points.

Transthoracic pressure changes were made at intervals between atmospheric pressure and $5 \mathrm{cmH}_{2} \mathrm{O}$ below atmospheric pressure by a vacuum pump (Edwards High Vacuum RBF3) which was attached to inlet hole B of the plethysmograph. With the rear hole $\mathrm{C}$ of the plethysmograph open, plethysmographic pressure remained at that of the atmosphere, but when this hole was closed the plethysmographic pressure dropped sharply to the present level. Pressure changes and flow changes at the airways opening were detected as in the resistance technique. The flow changes were electrically integrated with respect to time (Sanborn 350-5000 B) to give tidal volume changes. Pressure and volume events were recorded on a UV paper recorder (Honeywell 2500) from which compliance determinations could be made (Fig. 3 ). Volume calibration of $0.5 \mathrm{ml} / \mathrm{cm}$ deflection was made by means of a clean dry syringe, and pressure calibration of $2 \mathrm{cmH}_{2} \mathrm{O} / \mathrm{cm}$ deflection was carried out by means of a water manometer.

During compliance determinations care was taken to ensure that the animal was in its normal resting position within the plethysmograph. Lower values were obtained if the animal was hunched up or stretched out. Both resistance and compliance determinations were normally completed in less than five minutes each.
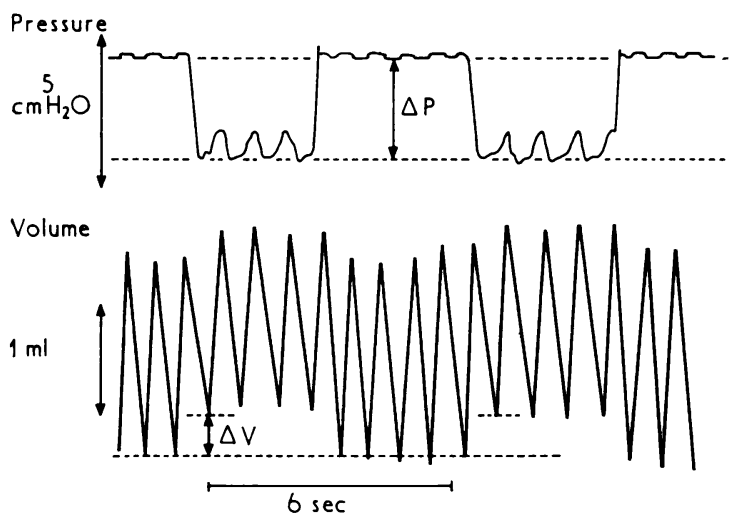

FIG. 3. Trace from a compliance record. Compliance is proportional to the ratio $\triangle V / \triangle P$.

\section{Results}

Frequency dependence of ventilatory impedance The measured impedance at a given frequency was independent of the amplitude of pressure oscillation applied, within the limits of 1 to $5 \mathrm{cmH}_{2} \mathrm{O}$ peak to peak. An amplitude of $4 \mathrm{cmH}_{2} \mathrm{O}$ was most frequently used. At frequencies below $15 \mathrm{~Hz}$ very little super- imposition of the sinusoidal pressure oscillation was detectable on the flow trace. This indicates that the impedance of the guinea-pig ventilatory system was high at such frequencies. Above $15 \mathrm{~Hz}$, however, a much better superimposition was obtained and hence frequencies above $15 \mathrm{~Hz}$ were of most interest in this study.

The mean impedances of a group of young animals of similar weight $(311 \mathrm{~g} ; \mathrm{SD} \pm 37 \mathrm{~g})$ measured at oscillation frequencies between 15 and $48 \mathrm{~Hz}$ are given in Table 1 and are plotted in Figure 4. A

\section{TABLE 1}

IMPEDANCE VAlues for a Group of Guinea-pigs BETWEEN 15 AND $48 \mathrm{~Hz}$

\begin{tabular}{c|c|c}
\hline $\begin{array}{c}\text { Frequency } \\
(\mathrm{Hz})\end{array}$ & $\begin{array}{c}\text { Number } \\
\text { tested }\end{array}$ & $\begin{array}{c}\text { Mean impedance value } \\
\left( \pm S \mathrm{~S} \mathrm{~cm} \mathrm{H}_{2} \mathrm{O} / \mathrm{ml} / \mathrm{sec}\right)\end{array}$ \\
\hline 15 & 9 & $1.40 \pm 0.34$ \\
20 & 5 & $0.93 \pm 0.32$ \\
25 & 11 & $0.57 \pm 0.12$ \\
32 & 11 & $0.38 \pm 0.10$ \\
40 & 10 & $0.57 \pm 0.09$ \\
48 & 9 & $0.76 \pm 0.24$ \\
\hline
\end{tabular}

typical resonance type curve was obtained with minimum impedance at $32 \mathrm{~Hz}$. At the point of minimum impedance the pressure/flow loops very nearly closed up to become straight lines, indicating an in-phase relationship between pressure and flow (Fig. 2). Looping was more marked on either side of this frequency.

Total ventilatory resistance measurement at the resonant frequency

The minimum impedance measured at resonance, where both pressure and flow are in phase, is equivalent to the resistive element of the system.

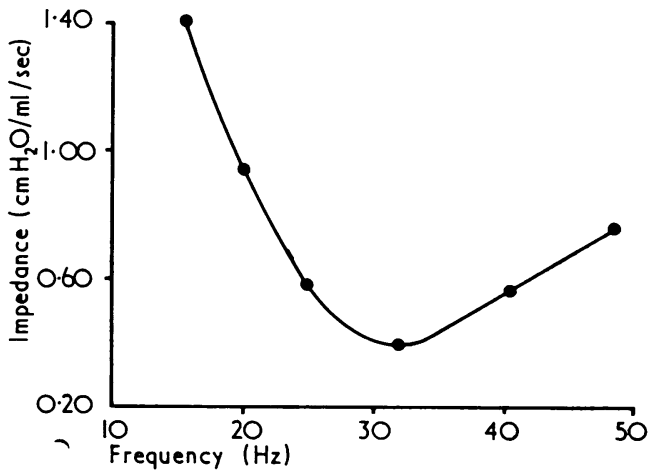

FIG. 4. Relation between frequency and impedance in a group of guinea-pigs. 
Many measurements were made at the resonant frequency to determine the repeatability. The total resistance for each animal was taken as the mean of four successive measurements in most cases, and typical values are given in Table 2 .

The coefficient of variation of such measurements was less than $10 \%$ in most cases, but high variation could sometimes occur, especially when animals were excited, thus preventing the face mask from being held snugly over the snout. Such high variability could be avoided by careful positioning of the animals, measurements being made only during quiet breathing.

A group of animals was investigated to determine animal to animal variation in resistance. The mean results for a group of 13 animals are given in Table 3. These results show that the coefficient of variation between animals is higher than that for repeated measurements on individual animals but is still less than $20 \%$. They also demonstrate a good repeatability between two separate tests within a day. Differences between repeated tests were not found to be significantly different by the modified $t$ test for small numbers $(d=0.76 ; D F=23 ; P>0.4)$.
The mean value of total resistance for a group of animals measured repeatedly over a period of several weeks showed further changes. Table 4 shows the results obtained for a group of guinea-pigs in which, although the resistance changed, the coefficient of variation of each test remained low.

The pulmonary resistance of guinea-pigs has been measured by Dennis et al. (1969), using an intrapleural catheter technique. Their results, and total resistance values for groups of animals of similar weight from this study, are given in Table 5.

\section{Total ventilatory compliance measurement}

The repeatability of this technique was tested, and the variabilities found for successive measurements on individuals are shown in Table 2. Again, the coefficient of variation was found to be less than $10 \%$ in most cases. The total compliance of each animal was usually taken as the mean of four measurements, and the results of repeated measurements in a single day for a group of 10 animals are given in Table 3. As before, the coefficient of variation between animals was less than $20 \%$, and the values obtained in two periods on the same day were

TABLE 2

Total Resistance and Compliance Values for Individual Guinea-pigs Measured Repeatedly

\begin{tabular}{|c|c|c|c|c|c|c|}
\hline \multirow{2}{*}{$\begin{array}{l}\text { Guinea- } \\
\quad \text { pig }\end{array}$} & \multicolumn{3}{|c|}{ Total resistance determinations } & \multicolumn{3}{|c|}{ Total compliance determinations } \\
\hline & $\begin{array}{c}N \\
\text { determinat ions }\end{array}$ & $\tilde{R} \pm S D\left(\mathrm{cmH}_{2} \mathrm{O} / \mathrm{ml} / \mathrm{sec}\right)$ & $C V \% 1$ & $\begin{array}{c}N \\
\text { determinations }\end{array}$ & $\bar{C} \pm S D\left(m l / c m H_{2} O\right)$ & $C V \%$ \\
\hline $\begin{array}{l}117 \\
118 \\
119 \\
120 \\
121 \\
122 \\
124 \\
126 \\
128 \\
130\end{array}$ & $\begin{array}{l}4 \\
5 \\
4 \\
4 \\
4 \\
4 \\
4 \\
5 \\
4 \\
4\end{array}$ & $\begin{array}{l}0.42 \pm 0.042 \\
0.42 \pm 0.020 \\
0.44 \pm 0.036 \\
0.34 \pm 0.036 \\
0.39 \pm 0.014 \\
0.40 \pm 0.013 \\
0.35 \pm 0.029 \\
0.42 \pm 0.042 \\
0.34 \pm 0.045 \\
0.44 \pm 0.010\end{array}$ & $\begin{array}{r}10 \\
5 \\
8 \\
11 \\
4 \\
3 \\
8 \\
10 \\
13 \\
2\end{array}$ & $\begin{array}{l}4 \\
4 \\
4 \\
5 \\
4 \\
4 \\
6 \\
4 \\
4 \\
4 \\
4\end{array}$ & $\begin{array}{l}0.15 \pm 0.012 \\
0.11 \pm 0 \\
0 \cdot 16 \pm 0.012 \\
0 \cdot 14 \pm 0.013 \\
0.13 \pm 0.020 \\
0.06 \pm 0.005 \\
0 \cdot 16 \pm 0.032 \\
0 \cdot 11 \pm 0 \\
0.18 \pm 0.006 \\
0.16 \pm 0.013\end{array}$ & $\begin{array}{r}8 \\
0 \\
7 \\
10 \\
15 \\
9 \\
20 \\
0 \\
3 \\
8\end{array}$ \\
\hline
\end{tabular}

${ }^{1}$ Coefficient of variation.

TABLE 3

Total Resistance and Compliance Values for a Group of Guinea-Pigs measured twice on One Day

\begin{tabular}{|c|c|c|c|c|c|c|}
\hline \multirow{2}{*}{$\begin{array}{l}\text { Experi- } \\
\text { mental }\end{array}$} & \multicolumn{3}{|c|}{ Total resistance determinations } & \multicolumn{3}{|c|}{ Total compliance determinations } \\
\hline & $\begin{array}{c}\text { Number } \\
\text { tested }\end{array}$ & $\bar{R} \pm S D\left(\mathrm{cmH}_{2} \mathrm{O} / \mathrm{ml} / \mathrm{sec}\right)$ & $C V \% 1$ & $\begin{array}{c}\text { Number } \\
\text { tested }\end{array}$ & $\widetilde{C} \pm S D\left(\mathrm{ml} / \mathrm{cmH}_{2} \mathrm{O}\right)$ & $C V \% 1$ \\
\hline $1 \stackrel{1}{2}$ & $\begin{array}{l}13 \\
13 \\
26\end{array}$ & $\begin{array}{l}0.59 \pm 0.11 \\
0.62 \pm 0.09 \\
0.61 \pm 0.10\end{array}$ & $\begin{array}{l}18 \\
15 \\
16\end{array}$ & $\begin{array}{l}10 \\
10 \\
20\end{array}$ & $\begin{array}{l}0.21 \pm 0.028 \\
0.19 \pm 0.035 \\
0.20 \pm 0.032\end{array}$ & $\begin{array}{l}13 \\
18 \\
16\end{array}$ \\
\hline
\end{tabular}

${ }^{1}$ Coefficient of variation. 
TABLE 4

Total Resistance and Compliance Values for a Group of Guinea-pigs measured over a Period of 16 WEEKS

\begin{tabular}{|c|c|c|c|c|c|c|}
\hline \multirow{2}{*}{$\begin{array}{l}\text { Weeks } \\
\text { after } \\
\text { first } \\
\text { measure- } \\
\text { ment }\end{array}$} & \multicolumn{3}{|c|}{ Total resistance determinations } & \multicolumn{3}{|c|}{ Total compliance determinations } \\
\hline & $\begin{array}{c}\text { Number } \\
\text { tested }\end{array}$ & $\bar{R} \pm S D\left(\mathrm{cmH}_{2} \mathrm{O} / \mathrm{ml} / \mathrm{sec}\right)$ & $C V \%$ & $\begin{array}{l}\text { Number } \\
\text { tested }\end{array}$ & $\bar{C} \pm S D\left(m l / c m H_{2} O\right)$ & $C V \% 1$ \\
\hline $\begin{array}{c}\text { First } \\
4 \\
8 \\
12 \\
16\end{array}$ & $\begin{array}{r}10 \\
10 \\
9 \\
8 \\
7\end{array}$ & $\begin{array}{l}0.33 \pm 0.031 \\
0.25 \pm 0.035 \\
0.25 \pm 0.014 \\
0.21 \pm 0.020 \\
0.23 \pm 0.022\end{array}$ & $\begin{array}{r}9 \\
14 \\
6 \\
10 \\
10\end{array}$ & $\begin{array}{r}10 \\
10 \\
9 \\
7 \\
7\end{array}$ & $\begin{array}{l}0.25 \pm 0.050 \\
0.33 \pm 0.057 \\
0.32 \pm 0.061 \\
0.37 \pm 0.063 \\
0.38 \pm 0.041\end{array}$ & $\begin{array}{l}20 \\
17 \\
19 \\
17 \\
11\end{array}$ \\
\hline
\end{tabular}

${ }^{1}$ Coefficient of variation.

TABLE 5

Comparison of Present Results with Pulmonary Values obtained by Dennis et al. (1969)

\begin{tabular}{|c|c|c|c|c|}
\hline Source & $\begin{array}{l}\text { No. of anima!s } \\
\text { tested }\end{array}$ & $\begin{array}{l}\text { Weight range } \\
\qquad(g)\end{array}$ & $\begin{array}{c}\text { Mean compliance } \\
(\text { and range }) \\
\left(\mathrm{ml} / \mathrm{cmH}_{2} \mathrm{O}\right)\end{array}$ & $\begin{array}{c}\text { Mean resistance } \\
(\text { and range }) \\
\left(\mathrm{cmH}_{2} \mathrm{O} / \mathrm{ml} / \mathrm{sec}\right)\end{array}$ \\
\hline $\begin{array}{l}\text { Dennis } \\
\text { et al. } \\
\text { (1969) }\end{array}$ & 9 & $250-350$ & $\begin{array}{l}0 \cdot 16^{1} \\
(0 \cdot 08-0 \cdot 70)\end{array}$ & $\begin{array}{l}0.34^{1} \\
(0.13-0.95)\end{array}$ \\
\hline \multirow{2}{*}{$\begin{array}{l}\text { Present } \\
\text { study }\end{array}$} & & $250-500$ & $\begin{array}{c}0.13^{2} \\
(0.07-0.19)\end{array}$ & $\begin{array}{c}0.40^{2} \\
(0.32-0.54)\end{array}$ \\
\hline & 19 & $600-900$ & $\begin{array}{c}0 \cdot 17^{2} \\
(0 \cdot 12-0 \cdot 27)\end{array}$ & $\begin{array}{c}0.31^{2} \\
(0 \cdot 20-0 \cdot 36)\end{array}$ \\
\hline
\end{tabular}

${ }^{1}$ Pulmonary value;

${ }^{2}$ total value

very similar $(\mathrm{d}=1 \cdot 41 ; \mathrm{DF}=17 ; \mathrm{P}>0 \cdot 10)$. Total compliance can change over a period of several weeks, as is shown for a group of animals in Table 4, but the coefficient of variation still remained under $20 \%$. Values of guinea-pig pulmonary compliance obtained by Dennis and his co-workers (1969), together with total compliance values for similar groups of animals from this study, are given in Table 5.

\section{Discussion}

The forced oscillation technique can be used for measuring the total ventilatory resistance of the guinea-pig ventilatory system as the system has the required resonance characteristics. Minimum impedance and minimum phase angle occurred at $32 \mathrm{~Hz}$, and the rather flat response over a number of cycles around the resonance frequency indicates that the system is well damped, thus preventing violent oscillation at such frequencies. Therefore, measurements at $32 \mathrm{~Hz}$ give the best estimate of the total resistance for the animals used in these experiments.
The coefficient of variation in physiological observations is an important factor when judging the sensitivity of a particular technique. For both total resistance and compliance, results can be obtained that have a coefficient of variation lower than $10 \%$. When groups of similar animals are investigated this value is still less than $20 \%$ in each case. These are very favourable when compared to results obtained for unanaesthetized guinea-pigs by a more involved technique (Amdur and Mead, 1958). These workers obtained coefficients of variation of $29 \%$ for resistance and $25 \%$ for compliance in a group of 200 animals of similar weight.

The changes in total resistance and compliance found for normal animals over long periods illustrate the need for testing well-matched control animals together with treated ones. The gradual increase in compliance and decrease in resistance may well be explained by increase in lung size as the animals were maturing during this time.

Using the techniques described, total ventilatory resistance and compliance are more easily deter- 
mined for experimental animals than either airway resistance or pulmonary compliance. Therefore the value of total ventilatory measurements when detecting changes in the lung alone requires discussion.

There is recent evidence (Macklem and Mead, 1967) suggesting that in dogs the tissue component of pulmonary resistance is negligible compared to airway resistance. If the tissue resistance of the thorax is also very small, then total ventilatory resistance is just as sensitive as airway resistance determination in detecting airway obstruction. This has indeed been quoted in the case of human beings by Grimby et al. (1968). The close similarity in values for pulmonary resistance quoted by Dennis et al. (1969), and total resistance quoted in this paper for animals of similar weight (Table 5), suggests that this is also the case in guinea-pigs.

Total compliance is a combination of pulmonary and thoracic compliance. These components are linked in such a way that the total compliance is less than either alone (Comroe et al., 1962). In humans, pulmonary and thoracic compliances have about the same value (Comroe et al., 1962). In guinea-pigs, there is a close similarity between the values for pulmonary compliance quoted by Dennis and his co-workers (1969) and total compliance found in this study for animals of similar weight (Table 5). This suggests that in guinea-pigs total compliance is related more closely to pulmonary than thoracic compliance. The thorax of a guinea-pig is light and contains quite flexible ribs which might, together with other factors, lead to a relatively high thoracic compliance. On the other hand, the lungs of such animals have small capacities which may contribute to other factors in causing a relatively lower pulmonary compliance. The larger the ratio between thoracic and pulmonary compliance, the more nearly total compliance reflects the pulmonary compliance alone.

The test procedures described allow measurements to be made during normal quiet breathing with the animal in its resting position. As such, they are relatively free from artefacts that are commonly encountered when anaesthetized animals are tested in unnatural positions. Each animal can be tested in less than 5 minutes, and this enables large groups to be examined regularly. The tests described are therefore believed to be adequately sensitive and practicable for long-term studies of ventilatory mechanics, and are at present being used in such studies following experimental inhalation of asbestos dust. These studies are to be reported later.

I am grateful to the Asbestosis Research Council for their support of this investigation. This work forms part of an M.Sc. thesis approved by Manchester University in 1971.

\section{References}

Amdur, M. O. and Mead, J. (1958). Mechanics of respiration in unanesthetised guinea pigs. American Journal of Physiology, 192, 364-368.

Comroe, J. H., Forster, R. E., DuBois, A. B., Briscoe, W. A., and Carlsen, E. (1962). The Lung, 2nd edition. Year Book Medical Publishers, Chicago.

Dennis, M. W., Douglas, J. S., Casby, J. U., Stolwijk, J. A. J., and Bouhuys, A. (1969). On-line analog computer for dynamic lung compliance and pulmonary resistance. Journal of Applied Physiology, 26, 248-252.

Grimby, G., Takishima, T., Graham, W., Macklem, P., and Mead, J. (1968). Frequency dependence of flow resistance in patients with obstructive lung disease. Journal of Clinical Investigation, 47, 1455-1465.

King, T. K. C. (1966). Mechanical properties of the lungs in the rat. Journal of Applied Physiology, 21, 259-264.

Macklem, P. T. and Mead, J. (1967). Resistance of central and peripheral airways measured by a retrograde catheter. Journal of Applied Physiology, 22, 395-401.

Mead, J. (1960). Control of respiratory frequency. Journal of Applied Physiology, 15, 325-336.

Swann, H. E., Brunol, D., and Balchum, O. J. (1965). Pulmonary resistance measurements of guinea pigs. Archives of Environmental Health, 10, 24-32.

Received for publication June 5, 1973.

Accepted for publication August 14, 1973 